\title{
The effects of anti-TNF agents on the expansion of $T$ helper-type 17 cells driven by lipopolysaccharide-stimulated monocytes
}

\author{
Gianluca Fossati ${ }^{*}$, Louise Healy, Andrew Nesbitt \\ From 7th European Workshop on Immune-Mediated Inflammatory Diseases \\ Noordwijk aan Zee, the Netherlands. 28-30 November 2012
}

\section{Introduction}

T helper-type 17 (Th17) cells are proinflammatory CD4+ cells characterized by Interleukin-17 (IL-17) production. Evidence suggests cytokines produce by Th17s, including IL-17, are involved in rheumatoid arthritis (RA) pathogenesis [1]. Lipopolysaccharide (LPS)-stimulated monocytes promote CD4+ cell differentiation into Th17 cells, producing IL-17 in vitro[2].

\section{Aim}

Examine the effect of 4 anti-tumor necrosis factor (TNF) agents (adalimumab, etanercept, infliximab, and certolizumab pegol) on $\mathrm{CD} 4+\mathrm{CD} 45 \mathrm{RO}+$ memory $\mathrm{T}$ cell expansion into Th17 cells, driven by LPS-stimulated monocytes.

\section{Patients and methods}

Monocytes and CD4+ cells were purified, by positive and negative selection, from peripheral blood mononuclear cells of healthy volunteers. CD $4+C D 45 R O+$ memory $\mathrm{T}$ cells were enriched from the CD4+ cell fraction by positive selection. A 1:1 ratio of monocytes and memory $\mathrm{T}$ cells was co-cultured for 7 days with CD3/CD28 Human T-Activator Dynabeads and $1 \mu \mathrm{g} / \mathrm{mL}$ LPS. Cells were cultured with and without $10 \mu \mathrm{g} / \mathrm{mL}$ anti-TNF agent. Subsequently, CD4+ cells were stained for intracellular Interferon $\gamma$ (INF $\gamma$ ) and IL-17A, and analyzed by flow cytometry. IL-17A and IL-17F secretion was determined by ELISA.

\section{Results}

IL-17A-producing CD4+ cell were 2.5-fold less frequent in co-cultures with the 4 anti-TNF agents compared to controls. IL-17A and IFN $\gamma$ producing CD4+ cell levels were similar between the 4 anti-TNF agents. Compared to controls, IL-17A and IL-17F secretion into the supernatant was lower in anti-TNF exposed co-cultures $(580 \mathrm{pg} /$ $\mathrm{mL}$ vs. $180 \mathrm{pg} / \mathrm{mL}$ and $8 \mathrm{ng} / \mathrm{mL}$ vs. $2 \mathrm{ng} / \mathrm{mL}$, respectively). There were no significant differences in the IL-17A or IL-17F concentration between co-cultures exposed to different anti-TNF agents.

\section{Conclusion}

Exposure to anti-TNF agents inhibited Th17 expansion and IL-17A production, suggesting that anti-TNF agents may reduce Th17 expansion and, as a consequence, IL-17A and IL-17F concentration.

Published: 28 November 2012

\section{References}

1. Pernis $A B$ : Th17 cells in rheumatoid arthritis and systemic lupus erythematosus. J Intern Med 2009, 265:644-52.

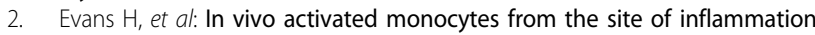
in humans specifically promote Th17 responses. Proc Natl Acad Sci U S A 2009, 106:6232-6237.

doi:10.1186/1479-5876-10-S3-P42

Cite this article as: Fossati et al:: The effects of anti-TNF agents on the expansion of T helper-type 17 cells driven by lipopolysaccharidestimulated monocytes. Journal of Translational Medicine 2012 10(Suppl 3): P42. 